\title{
Development of New Devices and Methods of Combined Processing for Obtaining Electrotechnical Wire Rod from Aluminium Alloys Al-Zr System
}

Sergey B. Sidelnikov, Nikolay N. Dovzhenko, Vadim M. Bespalov*, Denis S. Voroshilov, Tatiana N. Drosdova, Anton P. Samchuk and Ruslan E. Sokolov Siberian Federal University 79 Svobodny, Krasnoyarsk, 660041, Russia

This article represents research results of mechanical and electrical properties, and also microstructure of deformed semi-finished products from low alloyed alloys system Al-Zr, obtained using methods of combined rolling-extruding, combined casting and rolling-extruding with intensive plastic deformation.

Keywords: combined processing, rolling, extruding, electrical resistivity, mechanical properties, microstructure, aluminium, zirconium, wire, rolled wire.

DOI: 10.17516/1999-494X-2015-8-5-626-635.

(C) Siberian Federal University. All rights reserved

* Corresponding author E-mail address: vmbespalov@mail.ru 


\title{
Разработка новых устройств
}

\section{и способов совмещенной обработки}

для получения электротехнической катанки

\section{из алюминиевых сплавов системы Al-Zr}

\author{
С.Б. Сидельников, Н.Н. Довженко, \\ В.М. Беспалов, Д.С. Ворошилов, \\ Т.Н. Дроздова, А.П. Самчук, Р.Е. Соколов \\ Сибирский федеральный университет \\ Россия, 660041, Красноярск, пр. Свободный, 79
}

В статье представлены результаты исследований механических и электрических свойств, а также микроструктуры деформированных полуфабрикатов из низколегированных сплавов системы $\mathrm{Al}-\mathrm{Zr}$, полученных с помощьюю методов совмещенной прокатки-прессования, совмещенного литья и прокатки-прессования и интенсивной пластической деформации.

Ключевые слова: совмещенные процессы, прокатка, прессование, электросопротивление, механические свойства, микроструктура, алюминий, цирконий, проволока, катанка.

Большая потребность в алюминиевой кабельно-проводниковой продукции и достаточно высокий современный уровень технических требований, предъявляемых к ней, обусловливают необходимость проведения поисковых исследований, направленных на создание новых сплавов, устройств и способов изготовления электропроводников различной конфигурации, обеспечивающих достижение высоких эксплуатационных свойств последних.

Для их производства как в России, так и за рубежом наиболее подходят сплавы системы Al-Zr, обладающие повышенной термостойкостью и прочностью. Современный рынок кабельно-проводниковой продукции характеризуется наличием проволочных полуфабрикатов многих зарубежных фирм, среди которых Alstom, Nexans (Франция), Simens (Германия), Prysmian (Италия), NPA Skawina S.A. (Польша), J-Power Systems (Япония), Lumpi-Berndorf (Австрия), Southwire, General Cable, 3М (США) и мн. др. Все они занимают весомую долю на отечественном рынке и в целом создают огромную конкуренцию российским кабельным заводам. В России выпуск продукции в виде катанки из сплавов системы Al-Zr осуществляется на литейно-прокатных агрегатах (ЛПА) и существенно ограничен ввиду устаревшей промышленной базы отечественных предприятий. Прежде всего это связано с недостаточной прочностью прокатных станов для производства катанки из электротехнических сплавов алюминия, поэтому отечественные заводы вынуждены проводить модернизацию производственных мощностей путем замены существующего оборудования, причем преимущественно на импортное. В этой связи актуальной задачей становится поиск и проектирование принципиально новых энергосберегающих технологий и оборудования для получения длинномерных деформированных полуфабрикатов электротехнического назначения в виде катанки, прутков, проволоки и профилей.

Целью данной работы является создание комплекса технических и технологических решений, направленных на повышение эффективности производства длинномерных деформи-

$$
-627-
$$


рованных полуфабрикатов электротехнического назначения из сплавов системы Al-Zr на основе применения процессов совмещенной обработки металла. Ее актуальность подтверждается тем, что она выполнялась в рамках постановления Правительства РФ № 218 «О мерах государственной поддержки развития кооперации российских высших учебных заведений и организаций, реализующих комплексные проекты по созданию высокотехнологичного производства» в соответствии с договором Министерства образования и науки России № 13.G25.31.0083 по созданию высокотехнологичного производства по теме «Разработка технологии получения алюминиевых сплавов с редкоземельными, переходными металлами и высокоэффективного оборудования для производства электротехнической катанки», а также по договорам с ООО «РУСАЛ ИТЦ».

Для выполнения поставленной цели были разработаны новые технические решения в виде устройств для совмещенной обработки металла (рис. 1, 2), защищенные патентами РФ. Они позволили повысить эффективность использования прессового инструмента, снизить энергетические затраты, повысить производительность и выход годного металла.

На базе этих технических решений создана лабораторная установка непрерывного литья, прокатки и прессования СЛиПП-2,5, которая показана на рис. 3 , а ее технические характеристики приведены в табл. 1 .

Линия совмещенной обработки на базе этой установки включает в себя наклоняемую индукционную печь-миксер, деформирующий узел, ванну для охлаждения, калибровочную машину и моталку. Печь-миксер выполнена с регулятором подачи расплава и имеет общую емкость тигля по алюминию 350 кг. Деформирующий узел состоит из наклонной станины, в которой расположены валки, образующие закрытый ящичный калибр, перекрытый на выходе матрицей с помощью гидроцилиндра, и устройства для поджима валков гидравлического типа.

С использованием установок совмещенной обработки СЛиПП-2,5 и СПП-200 (табл. 1) были проведены экспериментальные исследования по получению прутков и проволоки из

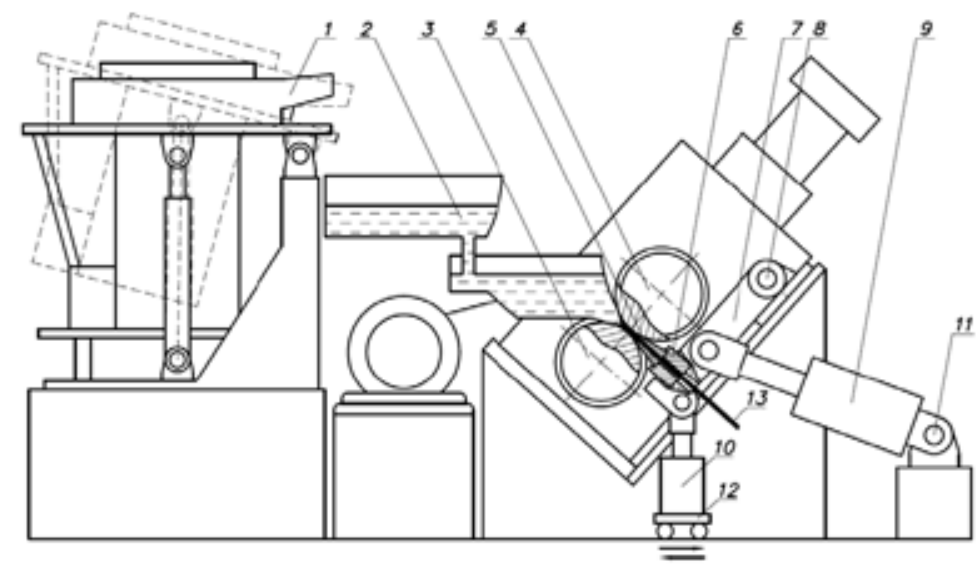

Рис. 1. Общий вид устройства для совмещенного литья и прокатки-прессования (СЛиПП) по патенту РФ № 128529: 1 - печь-миксер; 2 - литниковая система; 3 - валок с ручьем; 4 - валок с выступом; 5 - матрица; 6 - матрицедержатель; 7 - кронштейн; 8, 11, 12 - шарниры; 9 - гидроцилиндр; 10 - вертикальный гидроцилиндр 


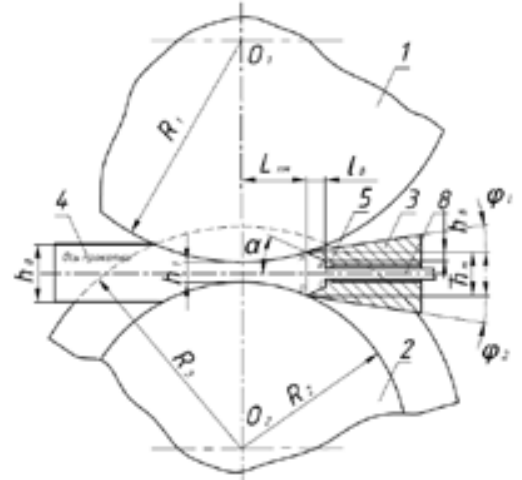

$a$

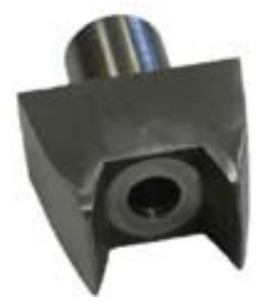

B

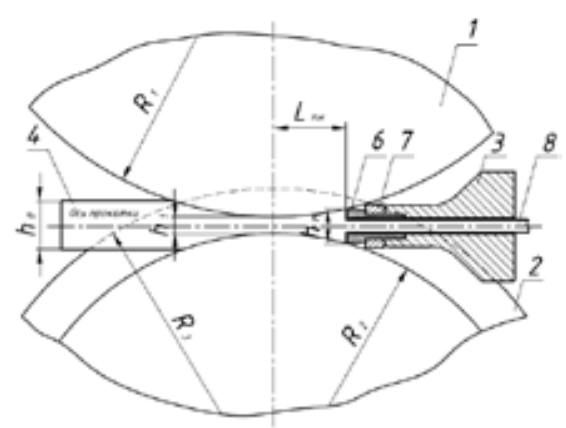

6

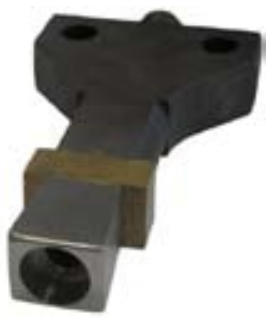

2

Рис. 2. Устройства для совмещенной прокатки и прессования (СПП) по патенту РФ № 138590 (а) и РФ № 139085 (б) и вид матричного инструмента (в, г): 1 - валок с выступом; 2 - валок с канавкой; 3 - матрица; 4 - заготовка; 5 - трапецеидальная выемка; 6 - калибрующая вставка; 7 - антифрикционная вставка; 8 - изделие

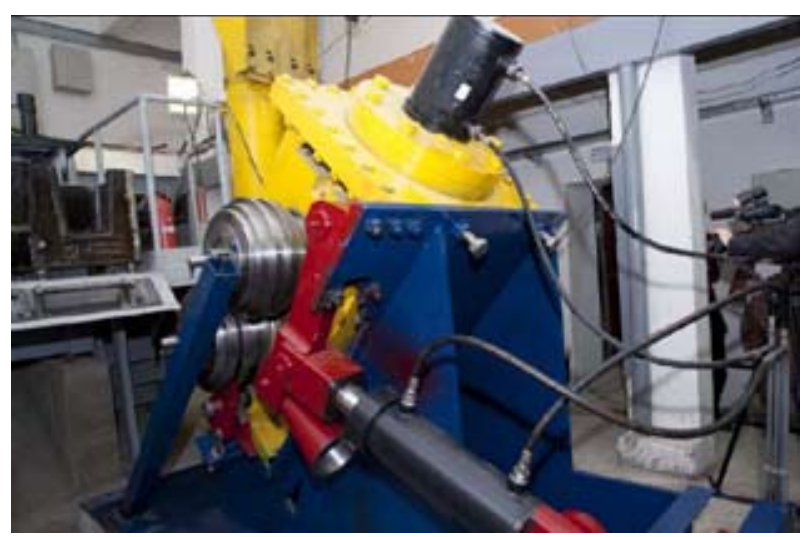

Рис. 3. Экспериментальная установка СЛиПП-2,5

сплавов системы Al-Zr. Для этого в лабораторных условиях ИЦМиМ были разработаны новые алюминиевые сплавы с добавками циркония в пределах $0,15-0,50$ мас. \% и получены слитки с различным химическим составом.

Низколегированные алюминиевые сплавы с добавками циркония в пределах $0,15-0,50 \%$ выплавляли в высокочастотной плавильной установке. Основным легирующим элементом в сплавах являлся цирконий, а железо и магний вводили дополнительно для повышения прочностных свойств. Для приготовления сплавов использовали цирконий в виде брикетов $(80 \%$ 
Таблица 1. Технические характеристики установок совмещенной обработки

\begin{tabular}{|l|c|c|}
\hline \multicolumn{1}{|c|}{ Параметры } & СПП-200 & СЛиПП-2,5 \\
\hline Начальный диаметр валка, мм & 200 & 480 \\
\hline Длина бочки валка, мм & 240 & 250 \\
\hline Диаметр шейки вала, мм & 100 & 150 \\
\hline Размеры ящичного калибра в наименьшем сечении, мм & $7 \times 15$ & $10 \times 22,20 \times 42$ \\
\hline Количество оборотов валка, об/мин & $4,8,14$ & 40 \\
\hline Передаточное число редуктора , ед. & 40 & 45 \\
\hline Мощность электродвигателя , кВт & 20 & 20 \\
\hline Момент на выходном валу, кН× м & 10 & 200 \\
\hline Рабочее давление гидростанции, кгс/см ${ }^{2}$ & $200-500$ & 300 \\
\hline Максимальное усилие прижима, кН & 300 & \\
\hline
\end{tabular}

Zr, остальное - флюс) фирмы Hoesch metallurgies GMBH (Германия). Предварительно просушенную лигатуру Al-Zr расчетного состава и массы вводили под зеркало расплава, предварительно нагретого до температуры 740-900 드 [1]. Расплав тщательно перемешивали от 1 до 3 мин, после этого подвергали выдержке в печи в интервале 5-20 мин и разливали в подогретые изложницы.

Некоторые прутки, полученные методом СЛиПП, подвергали обработке методом равноканального углового прессования (РКУП) на опытно-экспериментальной установке в Институте физики перспективных материалов Уфимского государственного авиационного технического университета [2]. Также проводили исследование опытных образцов катанки, полученной непрерывным способом литья-прокатки в промышленных условиях Иркутского алюминиевого завода (ОАО «ИркАЗ») [3].

В соответствии с технологией СПП заготовки размерами $14 \times 14 \times 250$ мм нагревали до температуры $550{ }^{\circ} \mathrm{C}$ и задавали в калибр валков, вращающихся со скоростью 4 об/мин. При проведении процесса способом СЛИПП полученный расплав подавали в калибр валков через специальное заливное устройство. В обоих случая получали на выходе пруток диаметром 9 мм. Метод РКУП проводили после термообработки с четырьмя циклами повторения при комнатной температуре. Опытные партии заводской катанки производили по серийной технологии ОАО «ИркАЗ» в соответствии с ТИ 445.02.02 и ВПУ 445.02.02.03 на литейно-прокатном агрегате. Расплав готовили в печи-миксере объемом до 20 т, поле чего по заранее подогретой литниковой системе металл подавали на колесо кристаллизатора и далее на прокатный стан, включающий 14 клетей. Температура расплава в миксере и перед фильтром кристаллизатора составляла 740-750 и 710-720 ${ }^{\circ} \mathrm{C}$ соответственно, а прутка диаметром 9,5 мм на выходе из прокатного стана $-310-320^{\circ} \mathrm{C}$.

В работе исследовали влияние состава сплавов, технологии изготовления и интенсивных пластических деформаций на физико-механические свойства и структуру деформированных полуфабрикатов.

Механические характеристики полученных образцов испытывали на машине Walter Bai AG LFM 400 и LFM 20 с усилием 400 и 20 кН в соответствии с требованиями ГОСТ 1497-84. 
Электросопротивление образцов $\rho$ измеряли с помощью милливольтметра «Виток» в соответствии с ГОСТ 7229-76. Результаты исследования механических свойств и удельного электросопротивления исследуемых образцов, полученных разными способами совмещенной обработки, представлены на рис. 4-6 и в табл. 2, 3 .

По мере повышения циркония в сплаве с 0,15 до 0,50 \% прочность прутков возрастает (рис. 4) в среднем на 4-5 \%, но одновременно происходит снижение электропроводности, что не совсем согласуется с требованиями по эксплуатационным характеристикам. Однако на примере алюминиевых сплавов с содержанием Zr 0,15-0,30 \% возможно достижение значительного снижения удельного электросопротивления применением специальной термической обработки. В частности, термообработка прутка, полученного методом СПП из сплава Al-0,30 \% Zr$0,20 \% \mathrm{Fe}$, проведенная по режимам термической обработки, привела к снижению электро-

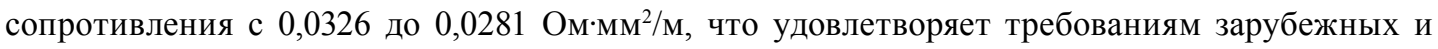
международных стандартов АSTM В941 и IEC 62004.

Анализ механических характеристик исследуемых образцов показал, что диапазон изменения временного сопротивления разрыву $\sigma_{B}$ составляет 110-200 МПа в зависимости от метода
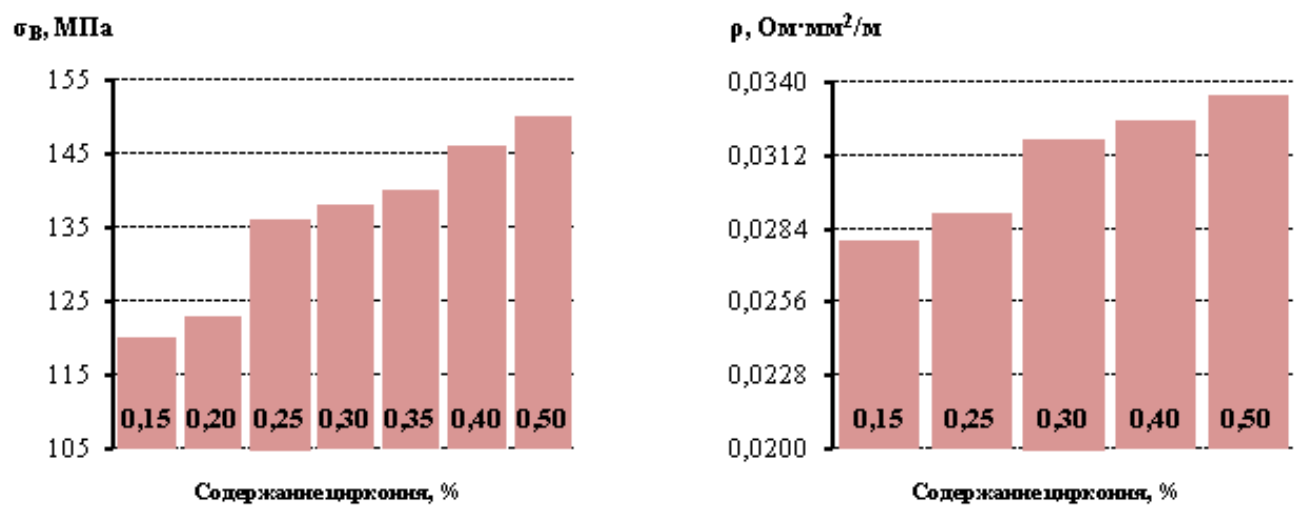

Рис. 4. Изменение временного сопротивления разрыву и удельного электросопротивления прутков с различным содержанием циркония, изготовленных методом СПП
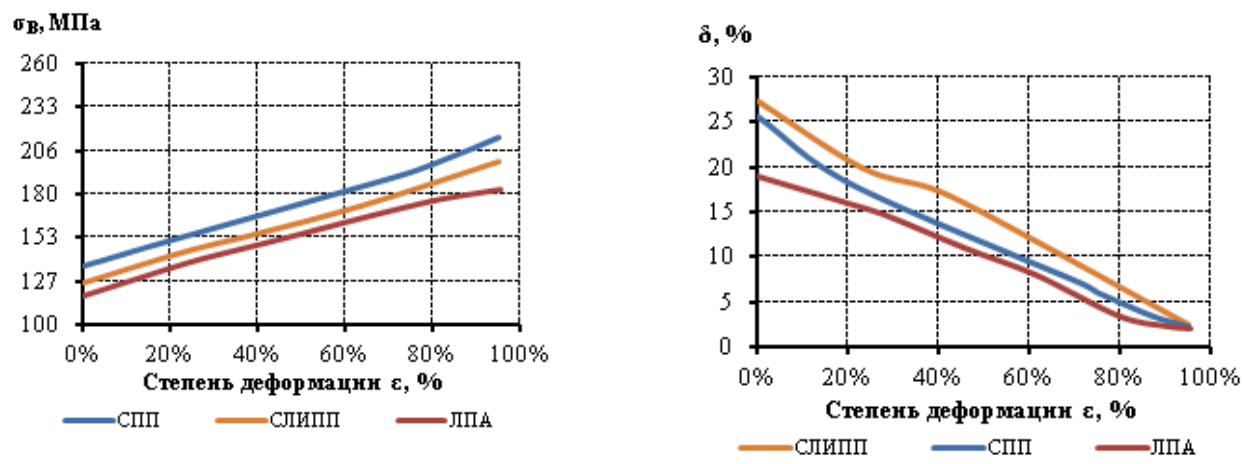

Рис. 5. Сравнение механических характеристик деформированных полуфабрикатов, полученных разными способами обработки из сплава Al-0,28 \% $\mathrm{Zr}-0,26 \% \mathrm{Fe}$ 

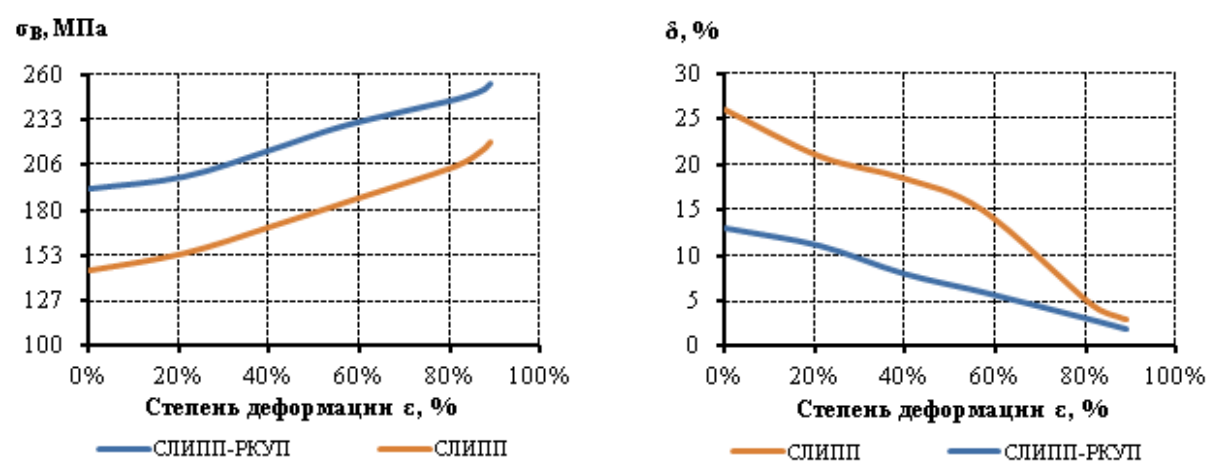

Рис. 6. Влияние ИПД на механические свойства деформированных полуфабрикатов из сплава Al-0,20\%Zr-0,30\%Mg

Таблица 2. Значения механических свойств и удельного электросопротивления деформированных полуфабрикатов из сплава Al-0,15 \% Zr-0,20 \% Fe, полученных разными способами обработки

\begin{tabular}{|l|l|l|l|l|}
\hline \multirow{2}{*}{ Способ } & \multicolumn{1}{|c|}{ Полуфабрикат, размеры } & $\sigma_{6}, \mathrm{MПа}$ & $\delta, \%$ & $\rho$, Ом·мм $^{2} / \mathbf{M}$ \\
\hline \multirow{2}{*}{ ЛПА } & Катанка, диаметр 9,5 мм & $110-120$ & 18,71 & $0,0305-0,0309$ \\
\cline { 2 - 5 } & Проволока, диаметр 2 мм & $190-200$ & 1,55 & $0,0310-0,0320$ \\
\hline \multirow{2}{*}{ СПП } & Прутки, диаметр 9 мм & $120-140$ & 17,0 & $0,0291-0,0309$ \\
\cline { 2 - 5 } & Проволока, диаметр 2 мм & $210-220$ & 2,5 & $0,0296-0,0311$ \\
\hline \multirow{2}{*}{ СЛиПП } & Прутки, диаметр 9 мм & $110-120$ & 24 & $0,0284-0,0298$ \\
\cline { 2 - 5 } & Проволока, диаметр 2 мм & $190-200$ & 3,65 & $0,0285-0,0307$ \\
\hline
\end{tabular}

Таблица 3. Значения механических свойств и удельного электросопротивления деформированных полуфабрикатов из сплава Al-0,20 \% Zr-0,30 \% Mg, полученных разными способами обработки

\begin{tabular}{|l|l|l|c|c|}
\hline \multicolumn{1}{|c|}{ Способ } & \multicolumn{1}{|c|}{ Полуфабрикат, размеры } & $\sigma_{\theta}$, МПа & $\delta, \%$ & $\rho$, Ом·мм²/м $^{2}$ \\
\hline \multirow{2}{*}{ СЛиПП } & Прутки, диаметр 9 мм & $140-150$ & 25,9 & $0,0330-0,0334$ \\
\cline { 2 - 5 } & Проволока, диаметр 2 мм & $240-250$ & 2,6 & $0,0340-0,0349$ \\
\hline \multirow{2}{*}{ СЛиПП - ТО - 4 цикла РКУП } & Пруток, диаметр 9 мм & $190-200$ & 12,9 & $0,0290-0,0294$ \\
\cline { 2 - 5 } & Проволока, диаметр 3 мм & $250-260$ & 2,0 & $0,0293-0,0297$ \\
\hline
\end{tabular}

обработки. При этом значения $\sigma_{B}$ прутков, полученных способом СПП, выше в среднем на 7 и $13 \%$ по сравнению с прутками и катанкой, полученных методом СЛиПП и на ЛПА (рис. 5). Более значительное упрочнение прутков было достигнуто за счет применения метода РКУП с использованием интенсивной пластической деформации (ИПД). Временное сопротивление разрыву прутка из сплава Al-0,20 \% Zr-0,30 \% Mg, полученного способом СЛиПП, составило 145 МПа, а дальнейшая его обработка методом РКУП привела к повышению прочности на 33 \% (рис. 6). 
Микроструктурный анализ исследуемых образцов проводили на микроскопе Ахіо ObserberA1m, Carl Zeiss. Для этого изготавливали микрошлифы по методикам ООО «Митэла» на автоматизированных шлифовально-полировальных станках Saphir 520 (Германия) и расходных материалах фирмы Lam Plan (Франция). Микроструктура образцов представлена в табл. 4.

Во всех исследуемых слитках структура состоит из $\alpha$-твердого раствора на основе алюминия и включений избыточных фаз с Fe и $\mathrm{Si}$. По результатам микроскопического анализа в сплавах, в которых температура заливки превышала $800^{\circ} \mathrm{C}$, не обнаружены частицы $\mathrm{Al}_{3} \mathrm{Zr}$, что свидетельствует о полном растворении циркония в алюминиевом твердом растворе. В структуре слитков сплавов Al-0,20 \% Zr-0,20\%Fe и Al-0,23 \% Zr-0,28 \% Fe были обнаружены включения $\mathrm{Al}_{3} \mathrm{Zr}$ в виде тонких разветвленных кристаллов, что может быть результатом снижения температуры заливки до 710-790 ${ }^{\circ} \mathrm{C}$. Таким образом, для растворения циркония при получении слитков необходима температура плавки не ниже $800^{\circ} \mathrm{C}$. Снижение температуры заливки ниже $800{ }^{\circ} \mathrm{C}$ приводит к выделению первичных кристаллов $\mathrm{Al}_{3} \mathrm{Zr}$.

Исследование микроструктуры образцов, деформированных разными маршрутами обработки, показало, что в долевом сечении катанки, прутков и проволоки наблюдается строчечное расположении частиц в направлении деформации. В поперечном сечении катанки, полученной на ЛПА, наблюдается равномерное расположение дисперсных частиц по объему образца. Исследование прутков после СПП показало, что их структура сохраняет те же составляющие, что и в литом состоянии. В прутках, полученных из слитка сплава Al-0,20 \% Zr-0,20 \% Fe, помимо железосодержащих фаз отчетливо выделяются достаточно мелкие фазы $\mathrm{Al}_{3} \mathrm{Zr}$, различимые при увеличении 1000 крат.

Таблица 4. Микроструктура деформированных полуфабрикатов из сплава 1 , полученных разными маршрутами обработки

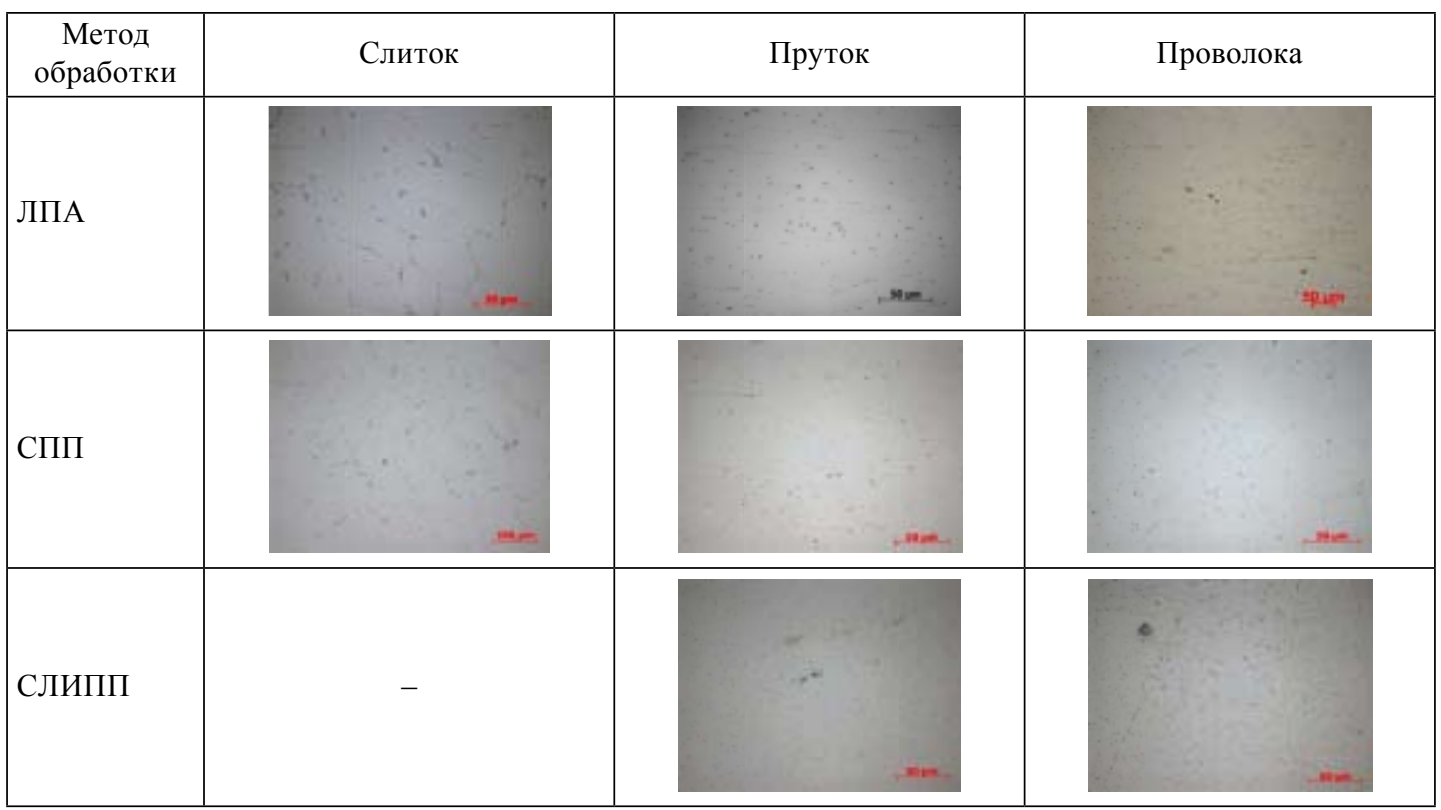


Структура всех образцов прутков, полученных по методу СЛИПП, характеризуется неоднородным распределением фаз по сечению алюминиевого твердого раствора (табл. 5). В отличие от прутков, полученных методом СПП, здесь наблюдаются более грубые скопления железосодержащих частиц и алюминидов циркония. Кроме того, в прутках обнаружены мелкие частицы $\mathrm{Al}_{3} \mathrm{Zr}$, чего не наблюдалось в слитках и деформированных заготовках данной плавки, полученных другими методами. Применение СЛиПП дает возможность получить деформированные и отожженные полуфабрикаты с достаточно хорошим сочетанием прочностных, пластических и электрофизических свойств, при этом пластические свойства выше, чем у полуфабрикатов, изготовленных способом СПП, что позволяет применять высокие суммарные степени деформации при волочении (до 95 \%) без использования промежуточных отжигов. Следует отметить также, что холодная деформация при получении проволоки приводит к дроблению частиц $\mathrm{Al}_{3} \mathrm{Zr}$, и они представляют скопления мелких, близких к округлой форме, частиц, тогда как в соответствующих прутках большинство частиц имеет пластинчатую форму.

Исследование микроструктуры образцов после РКУП проводили методом просвечивающей электронной микроскопии (ПЭМ) на микроскопе JEM-2100 фирмы Jeol при ускоряющем напряжении 200 кB, оснащенном приставкой INCA x-sight для проведения энергодисперсионного анализа наноразмерных элементов тонкой структуры. Электронно-микроскопический анализ прутков методом ПЭМ после обработки способом РКУП показал, что исходная структура сплава полностью трансформируется в УМЗ, а проведенный количественный анализ микроструктуры позволил оценить средний размер зерен после ИПД, который составил в среднем (647 \pm 29$)$ нм (табл. 5).

Проведенные экспериментальные исследования показывают принципиальную возможность получения деформированных полуфабрикатов с требуемым сочетанием физикомеханических характеристик. По сравнению с традиционными методами литья-прокатки на ЛПА применение способов СПП и СЛиПП обеспечивает получение высокого уровня механических характеристик деформированных полуфабрикатов при заметном сокращении переходов обработки. Кроме того, использование метода РКУП, отличающегося более высокой интенсивностью пластической деформации, в сочетании со способами СПП и СЛиПП позволяет добиться дополнительного упрочнения прутков и проволоки за счет формирования в них УМЗ структуры с размерами зерен 618-676 нм.

Таблица 5. Микроструктура деформированных полуфабрикатов из сплава 4, полученных разными маршрутами обработки

\begin{tabular}{|c|c|c|}
\hline Полуфабрикат & СЛиПП & СЛиПП-РКУП \\
\hline Пруток диаметром 9 мм & &
\end{tabular}




\section{Выводы}

1. Для промышленного внедрения можно рекомендовать сплавы с содержанием циркония и железа на уровне $0,15-0,20 \% \mathrm{Zr}$ и 0,10-0,15 \% Fe для изготовления проволоки типа AT1 по стандарту IEC 62004-07 без термической обработки, а также 0,25-0,30 \% Zr и 0,2-0,25 \% Fe для состояния проволоки АТ3 с термической обработкой.

2. Деформированные полуфабрикаты, полученные способом совмещенной прокаткипрессования, отличаются повышенными прочностными характеристиками и достаточной технологичностью при дальнейшей холодной обработке, а прутки и проволока, полученные способом совмещенного литья, прокатки и прессования, обладают более высокими пластическими свойствами и электропроводностью.

3. Сочетание при обработке сплавов системы Al-Zr способов совмещенной обработки и интенсивной пластической деформации позволяет добиться дополнительного повышения прочностных характеристик деформированных полуфабрикатов из сплавов системы Al-Zr и достичь при изготовлении проволоки требований стандарта IEC 62004-07 по типу АT2.

\section{Список литературы}

[1] Прохоров А.Ю., Белов Н.А., Алабин А.Н. // Литейщик России. 2010. № 4. С. 30-34.

[2] Рааб Г.И., Мурашкин М.Ю., Валиев Р.3. // Цветные металлы-2011: Сб. докладов межд. ІІІ международного конгресса. Красноярск, 2011. С. 500-501.

[3] Трифоненков Л.П., Довженко Н.Н., Сидельников С.Б. и др. Цветные металлы-2011: Сб. докладов III Международного конгресса. Красноярск, 2011. С. 560-563. 